\begin{tabular}{|l|l|l|}
\hline \multicolumn{2}{|c|}{ PublisherInfo } \\
\hline \hline PublisherName & $:$ & BioMed Central \\
\hline \hline PublisherLocation & $:$ & London \\
\hline \hline PublisherImprintName & $:$ & BioMed Central \\
\hline \hline
\end{tabular}

\title{
Therapeutic potential of TACI-Ig in treatment of arthritis
}

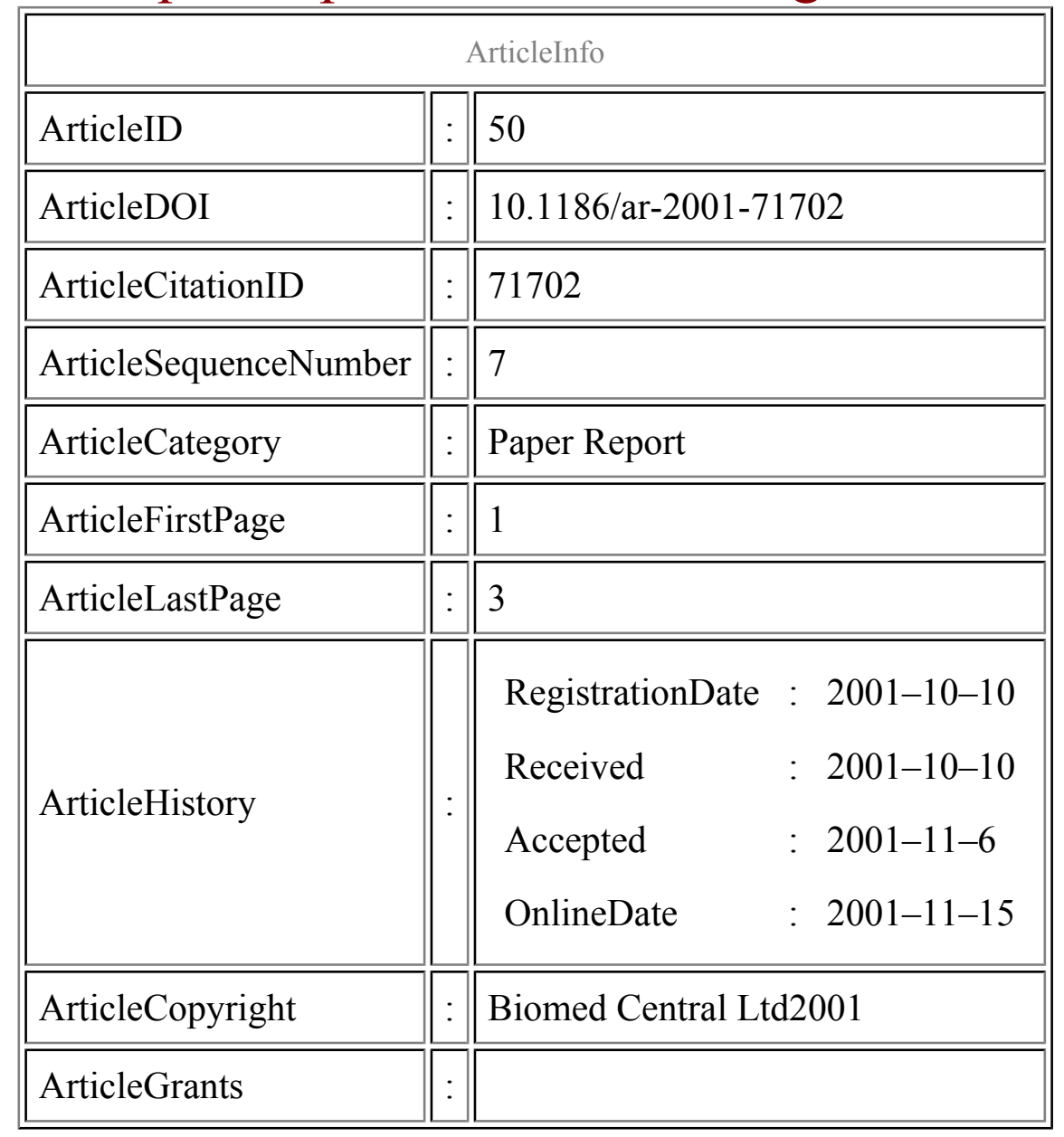




\begin{tabular}{|l|l|l|}
\hline ArticleContext & $:$ & 130753311 \\
\hline
\end{tabular}

Virginia Smith Shapiro, ${ }^{\text {Aff1 }}$

Aff1 University of Pennsylvania, U.S.

\section{Keywords}

Arthritis, BLyS, CIA, TACI-Ig

\section{Context}

BLyS (BAFF, TALL-1, THANK, zTNF4) and APRIL are members of the TNF family that modulate B-cell activation and survival. TACI and BCMA are two previously characterized receptors for BLyS that also bind to APRIL. Transgenic animals that overexpress BLyS develop symptoms similar to SLE. Recombinant TACI-Ig decreases disease severity and frequency in SLE susceptible mice, thus, implicating BLyS in the development of SLE and, perhaps, autoimmune disorders in general. Elevated levels of BLyS are also observed in the serum of RA patients. In this study, the effect of TACI-Ig on arthritis in a mouse model of CIA was examined.

\section{Significant findings}

Injection of TACI-Ig prior to the second collagen injection in male DBA/1 mice delayed the onset and decreased the severity of disease and decreased the percentage of animals that developed CIA. To determine the effects of TACI-Ig in a manner resembling treatment of existing disease, TACI-Ig treatment initiation was delayed until 7 days after the second injection, when $52 \%$ of the animals developed anticollagen antibodies and demonstrated signs of inflammation. Again, TACI-Ig treatment inhibited disease progression, decreasing both inflammation and the percentage of animals that progressed to established disease. Thus, TACI-Ig is a novel therapeutic agent for autoimmune disease, including arthritis, with great clinical potential. In both TACI-Ig transgenic and BLyS-deficient mice decreases in mature B cells were observed, implicating BLyS in B-cell development. However, TACI-Ig injections into normal mice caused a significant decrease in the number of mature B cells, although immature B-cell populations were unaffected. 


\section{Comments}

The use of TACI-Ig to inhibit the progression of CIA after the onset of inflammation and generation of anticollagen antibodies demonstrates its clinical potential in treating RA and other autoimmune disorders. Given previous implications for BLyS in autoimmune disease, the mechanism of action of TACI-Ig is presumably inhibition of BLyS, and not its other ligand, APRIL. The authors suggest that BLyS is not directly involved in B-cell development, but in maintaining homeostasis of mature B-cell populations. Presumably, TACI-Ig exerts its effects in murine models of RA through deletion of mature, autoreactive B cells (although this was not explicitly examined). Recently, a novel receptor for BLyS has been cloned that does not bind APRIL (see Additional information [1]); future work will elucidate whether this new receptor is the relevant target in TACI-Ig inhibition of CIA. Another group generated a BLyS-deficient animal with similar phenotype (see Additional information [2]).

\section{Methods}

CIA model, gene targeting, knockout mice, transgenic mice

\section{Additional information}

1. Thompson JS, Bixler SA, Qian F, Vora K, Scott ML, Cachero TG, Hession C, Schneider P, Sizing ID, Mullen C, Strauch K, Zafari M, Benjamin CD, Tschopp J, Browning JL, Ambrose C: BAFF$\mathbf{R}$, a newly identified TNF receptor that specifically interacts with BAFF. Science 2001, 293:2108-2111 (Paper report).

2. Schiemann B, Gommerman JL, Vora K, Cachero TG, Shulga-Morskaya S, Dobles M, Frew E, Scott ML: An essential role for BAFF in the normal development of B cells through a BCMA-independent pathway. Science 2001, 293: 2111-2114 (PubMed abstract).

\section{References}

1. Gross JA, Dillon SR, Mudri S, Johnston J, Littau A, Roque R, Rixon M, Schou O, Foley KP, Haugen H, McMillen S, Waggie K, Schreckhise RW, Shoemaker K, Vu T, Moore M, Grossman A, Clegg CH: TACI-Ig neutralizes molecules critical for B cell development and autoimmune disease: impaired B cell maturation in mice lacking BLyS. Immunity. 2001, 15: 289-291. 